\title{
High Altitude Makes for High Energy
}

\author{
Scenario Forum Symposium at the University of Northern \\ Colorado, USA, January 19-20, 2018
}

\section{Tin Wegel}

On January 19, 2018 about 80 people sat in an unassuming conference room on the campus of the University of Northern Colorado in Greeley, chatting and signing away cheerfully with their seat neighbors in anticipation of the keynote address by Susanne Even from Indiana University in Bloomington, IN. The lively crowd of students and faculty members from across the country was clearly already in a chatty mood before the official introduction by Erin Noelliste, the lead organizer of the $5^{\text {th }}$ Scenario Symposium on Performative Pedagogy, kicked off an engaging and interactive evening and day ahead. The idea behind this particular symposium was to focus on the use of drama to enhance learning in education and foreign languages, as the program stated. It was the second of its kind held in the US and thus aimed at broadening readership and scope of the Scenario Journal, with the goal of inspiring creativity and improvisation in foreign language classrooms.

The keynote speaker Susanne Even took the podium and I dare say she could not have hoped for a more involved group of lifelong learners. Her keynote talk, made accessible to all participants by sign language interpreters, was the first presentation in the 2018 Schulze Speaker Series at UNC, titled: "Performative Pedagogy - Crossroads of the Arts, Education, and Foreign Languages." Susanne Even's talk brought to life her ideas of fusing together interdisciplinary fields in education to show how drama enhances learning in a myriad of classroom situations. Anyone who has ever read articles by Susanne knows that her depth of knowledge about performative pedagogy means that she could easily speak for hours about it, but anyone who has ever seen her speak also knows that lecturing at length is not her style. Instead, in an interactive environment, we, as her willing audience, got the chance to participate to the greatest extent possible both with words and action. One of the highlights with regard to audience participation might have been the moment when an unsuspecting star performer in the Hot Seat (a participatory activity in which someone assuming a pre-determined character has to answer impromptu questions from the audience), a young woman from UNC, briefly stole the show in the best sense of the word during her time on stage. Susanne Even's talk was followed by a reception during which everyone had a chance to get to know each other better before the presentations continued the next day.

Promptly at 8 AM - yes, 8 AM! - the next morning, we all gathered for some breakfast prior to the first of three presentations. After a sincere and 
enthusiastic welcome by Laura Connolly, the Dean of the UNC College of Humanities and Social Science, Tin Wegel from the other UNC (University of North Carolina at Chapel Hill) took the podium to talk about staging full-length theater plays in the foreign language classroom at the college level. Following in Susanne Even's footsteps from the night before, Tin Wegel made full use of the audience's enthusiasm to have six participants stage three different impromptu performances of the same mini-play written by one of her former students at UNC-CH. This exercise drew attention to the variability with which one and the same script could be read, interpreted, and subsequently staged.

After a short coffee break, Lane Sorensen from Indiana University in Bloomington really got our tongues rolling and our bodies moving when he allowed us to "Let Foreign Language Move You with Drama Pedagogy". His two-hour workshop was expertly crafted and allowed everyone to take the stage over and over again and enact feelings of power as a fairy-tale character of our choice. Not only did we have a lot of fun slaying evil, we also appreciated all of the concrete examples and directions given which could be applied to the FL classroom and took away a chest full of enchanting activities to try with our own students at all levels of language proficiency.

After lunch we all gathered again for our final workshop of this symposium. Erin Noelliste from the University of Northern Colorado and Joseph Noelliste from Elon University drew out our best singing voices, or the best resemblance of those, as part of their workshop on "Mnemonics in Foreign Language Pedagogy". The energy that reverberated through the audience was plenty evidence for the sustained engagement that everyone had brought to this symposium for which we all have to thank, in no small parts, Erin Noelliste who made everyone feel comfortable and at home. Both Erin and Joseph Noelliste convincingly showed in their workshop that we can all work with music in the FL classroom in order to enhance engagement and retention. This could not have been made more evident than through the full participation by a group of students and educators from the UNC master's program in Special Education with an emphasis on Deaf and Hard of Hearing. Their improvised presentation of an original song in sign language served as a powerful reminder that learning and a love for performance bridges all perceived divides and brings us all closer together. I, for one, felt profoundly moved mentally, physically, and emotionally by this symposium and its many participants from such an array of backgrounds.

The symposium concluded with a brief roundtable discussion and closing remarks by Don Holman, the Chair of the UNCDepartment of Modern Languages, which underscored, in conjunction with Dean Connolly's opening remarks, the growing interest in and recognition of the importance of performative pedagogy by faculty members at all levels of the administration. UNC offered a fertile ground for this symposium as this institute of higher education prides itself on its strong support for teaching and pedagogy, which was made evident by how open and excited participants from numerous departments were to sharing ideas with peers from other areas during the talks and workshops. The enthusiasm for the topic spread to lunch time, when we continued to informally 
exchange ideas and stories from our own experiences with drama pedagogy. At the conclusion of this $5^{\text {th }}$ Scenario Forum Symposium, all participants left with a new arsenal of inspiring ideas on how performance can be used to enhance language learning with plays, music, and improvisation theatre activities. 